\title{
Impact of Happiness on Allocation in Real Estate in Chinese Household
}

\author{
Ya-ling ZHOU ${ }^{1}$ and Zhong-yi XIAO ${ }^{2}$ \\ ${ }^{1}$ College of Economics and Management, Southwest University, Chongqing, 400716, \\ P.R. China \\ ${ }^{2}$ School of Economics, Southwest University of Political Science and Law, Chongqing, \\ 401120, P.R. China
}

Keywords: Happiness, Real estate, China, Household, Optimism.

\begin{abstract}
This article utilizes the data from China Household Finance Survey in 2011 to study the relationship between happiness and investment in real estate market. The result indicates the probability of a household's participation in real estate, as well as household shares invested in it, is strongly associated with happiness. Furthermore, empirical results suggest optimism triggers a potential channel to affect household's allocation in real estate market.
\end{abstract}

\section{Introduction}

Household finance is new branch field of economic study, and it attract much recent interest. Conventional economist focuses on the asset pricing in the capital markets and the return generating process. Recent, many of them turn to ask how households use financial tools to attain their objectives (Campbell, 2006). Tufano (2009) suggest a functional definition of the subfield of household finance, focusing on four key functions, such as payments, risk management, tradeoff between consumption and saving or investing, borrowing.

Most of previous studies related to the stock market participation. Vising-Jorgensen (2002) found participation of stock market is positively related to the family wealth, the rich family inclined to participated in stock market deeply. The highly educated households increase their capability to invest in stock market (Berhheim and Garrett, 1996). Previous empirical studies also concluded that back ground income risk (Guiso et al., 1996), health status (Rosen and Wu, 2004), social network (Hong et al., 2004) are associated with the asset allocation of households.

Recent neurological and psychological studies have shown that happiness might play a pivotal role in decision making (Gilbert 2006).Kahn and Isen (1993) document that happy individuals save and spend different proportions of their income, and acquire different combinations over time. Frey and Stutzer (2002) suggest that the extent of happiness might influence many important economic decisions, such as consumption activities, work behavior, political behavior, as well as investment behavior. Guven (2012) suggests that happy people are found to save more, spend less, and shows a lower marginal propensity to consume. Additionally, Rao et al. (2014) indicated that a household's propensity of investing in stocks or mutual funds in China, as well as household asset shares invested in stocks or mutual funds, is strongly associated with happiness. Of particular goods and services, compared with 
unhappy individuals. Nevertheless, the study on effects of happiness on the asset share invested in real estate is lagged. In fact, real estate, housing, is an asset of asset class of dominant importance for Chinese household. Housing, unlike stock, is long-term assets that deliver a stream of housing serviced to their owners, but are also illiquid assets.

In sum, this context explores the empirical study to not only investigate the role of happiness on the probability of participation in real estate market but also the proportion of asset share. Also this article contributes to the empirical evidence on the related mechanisms.

\section{Data and Model}

This study implements the first wave investigation of China Household Financial Survey, CHFS, which was conducted in 2011 and released by the Research and Survey Center for China Household Finance. This survey provides a national-wide representative data, including 8438 households and 29500 individuals across China in term of both rural and urban. It also shows a wide range of topics covering information on age, number of family members, education status, marriage status, social capital, social networks, and etc.

To investigate the impact of happiness on the investment in real estate, this article set two null hypothesizes: first, the happiness of individual has no effect on the participation of real estate; second, the happiness of individual has no effect on the proportion of investment in real estate. Therefore, this article implements the empirical model as Equitation (1) (2).

$\operatorname{Prob}\left(\operatorname{RESTATE}_{i}=1\right)=\alpha_{0}+\alpha_{1} \cdot$ Happiness $_{i}+\lambda \cdot X+\varepsilon_{i}$.

RESTATE $_{i}=\alpha_{0}+\alpha_{1} \cdot$ Happiness $_{i}+\lambda \cdot X+\zeta_{i}$.

This article adopts the real estate market participation indicator by asking whether households own real estate. The households participated was assigned number 1, otherwise 0. RESTATE measures the proportion of investment in real estate for each individual.

To create the happiness indicator, this article depends on the subjective question in CHFS: "In general, do you feel happy now?" the one answers could be selected among "very unhappy", "unhappy", "fair", "happy", "very happy”, with corresponding scores ranging from 1 to 5 . The $\mathrm{X}$ represents a set of control variables: family size, age, education, family income, and risk aversion. This context also controlled demographic location and place of residence (rural or urban). Also note that happiness may still be an endogenous regressor in specifications that might make the coefficient estimates biased and inconsistent. Therefore, this article adopts ecological environment as instrumental variable to address the potential endogeneity of happiness.

In addition, happiness might also be related to optimism, thus indirectly influencing real estate market participation and investment amount. To construct an optimism indicator, we use the following questions: "How do you predict the development of the Chinese economy in the next 3-5 years?" The answers could be "very bad", "bad", "unchanged", "good", and "very good", with corresponding scores ranging from 1 to 
5. The signed the individual scored above 4 as optimism in this study.

\section{Empirical Results}

Table 1 provides summary on statistics of happiness. It shows that the sample consist of 8421 households excluding samples with invalid responses from the household head. The respective response rates for the question of happiness level are very unhappy (1.08\%), unhappy (5.56\%), fair (30.01\%), happy $(48.31 \%)$, or very happy $(15.05 \%)$. The mean happiness is 3.71 for the entire CHFS sample.

Table 1. Distribution of Happiness

\begin{tabular}{|l|c|c|c|c|c|}
\hline & Very Unhappy & Unhappy & Fair & Happy & Very Happy \\
\hline Observation & 91 & 468 & 2527 & 4068 & 1267 \\
\hline Weight & $1.08 \%$ & $5.56 \%$ & $30.01 \%$ & $48.31 \%$ & $15.05 \%$ \\
\hline
\end{tabular}

Table 2. The influence of happiness on real estate allocation

\begin{tabular}{|c|c|c|c|c|}
\hline & Probit & IV/Probit & Tobit & IV/Tobit \\
\hline & (1) & (2) & (3) & (4) \\
\hline \multirow{2}{*}{ Happiness } & $0.1106 * * *$ & $1.0350 * * *$ & 0.0059 & $0.2086 * *$ \\
\hline & $(0.0258)$ & $(0.1489)$ & $(0.0051)$ & $(0.1060)$ \\
\hline \multirow[t]{2}{*}{ Self-employment } & -0.0153 & -0.0843 & $-0.1552 * * *$ & $-0.1707 * * *$ \\
\hline & $(0.0748)$ & $(0.0520)$ & $(0.0142)$ & $(0.0167)$ \\
\hline \multirow[t]{2}{*}{ Family Size } & $0.2911 * * *$ & $0.2136 * * *$ & $0.0483 * * *$ & $0.0544 * * *$ \\
\hline & $(0.0425)$ & $(0.0564)$ & $(0.0153)$ & $(0.0187)$ \\
\hline \multirow[t]{2}{*}{ FamilySize $^{2}$} & $-0.0215 * * *$ & $-0.0161 * * *$ & $-0.0041 * *$ & $-0.0047 * *$ \\
\hline & $(0.0049)$ & $(0.0055)$ & $(0.0018)$ & $(0.0022)$ \\
\hline \multirow[t]{2}{*}{ Age } & $0.0757 * * *$ & $0.0723 * * *$ & $0.0139 * * *$ & $0.0191 * * *$ \\
\hline & $(0.0083)$ & $(0.0108)$ & $(0.0022)$ & $(0.0032)$ \\
\hline \multirow[t]{2}{*}{$\mathrm{Age}^{2}$} & $-0.0006 * * *$ & $-0.0007 * * *$ & $-0.0001 * * *$ & $-0.0002 * * *$ \\
\hline & $(0.0001)$ & $(0.0001)$ & $(0.0000)$ & $(0.0000)$ \\
\hline \multirow[t]{2}{*}{ Risk Aversion } & -0.0354 & 0.0438 & $0.0320 * * *$ & $0.0498 * * *$ \\
\hline & $(0.0726)$ & $(0.0547)$ & $(0.0122)$ & $(0.0164)$ \\
\hline \multirow[t]{2}{*}{ Education } & $0.0221 * * *$ & 0.0049 & 0.0023 & 0.0003 \\
\hline & $(0.0072)$ & $(0.0074)$ & $(0.0016)$ & $(0.0018)$ \\
\hline \multirow[t]{2}{*}{ Married Status } & $0.1489 * *$ & $0.2016 * *$ & $0.0508 * * *$ & -0.0095 \\
\hline & $(0.0658)$ & $(0.0893)$ & $(0.0162)$ & $(0.0358)$ \\
\hline \multirow[t]{2}{*}{ Internet Utilization } & $0.2252 * * *$ & $0.0910^{*}$ & 0.0061 & -0.0030 \\
\hline & $(0.0688)$ & $(0.0551)$ & $(0.0102)$ & $(0.0126)$ \\
\hline \multirow[t]{2}{*}{ Family Income } & $0.0476 * * *$ & -0.0028 & 0.0010 & -0.0061 \\
\hline & $(0.0087)$ & $(0.0135)$ & $(0.0026)$ & $(0.0043)$ \\
\hline \multirow[t]{2}{*}{ Rural Dummy } & $0.4232 * * *$ & $0.2000 *$ & $-0.0777 * * *$ & $-0.0935 * * *$ \\
\hline & $(0.0984)$ & $(0.1060)$ & $(0.0181)$ & $(0.0199)$ \\
\hline County Dummy & Yes & Yes & Yes & Yes \\
\hline Observations & 7790 & 8180 & 8176 & 7950 \\
\hline
\end{tabular}

Notes: Robust standard errors are in parentheses. * Significant at the $10 \%$ level; ** Significant at the $5 \%$ level; *** Significant at the $1 \%$ level.

Table 2columns (1) and (2) report that the impact of Subjective Well-being on the Real Estate Participation. The regression in column (1) is run by OLS with probit model. The result shows that the coefficient of happiness variable is 0.111 , which is statistically significant at 1 percentage level, implying that happiness might play an 
important on household's decision in participating in real estate market. In column (2), by incorporating instrument variable to address the potentially endogeneity, the estimated coefficient of happiness was increased by 1.035 , which is also statistically significant at the 1 percentage level. These results suggest that happiness influence a household's decision regarding whether put money into real estate market.

Results for control variables are as follows. The coefficient of family size is significantly positive with a negative coefficient of FamilySize ${ }^{2}$ at 1 percentage level, suggesting an inverse U-shaped relationship between family size and probability of real estate market participation. The similar relation is also found between age of family head and probability of real estate market participation. Also note that the status of heathy relation in marriage status also improve the probability of real estate market participation.

Next, this article examines whether happiness influences the proportion of wealth that household invest in real estate market. Table 2 also shows the results run by OLS with the Tobit model and IV/Tobit with instrument variable, respectively. As column (4) illustrates, the result shows that coefficient of the happiness is 0.209 and statistically significant at 5\% level, implying that happiness displays a strong influence on the share of wealth that a household invests in real estate market. In fact, it is consistent with the prediction. Furthermore, the results suggest that the variable of risk aversion, age, marital status, place of residence also impact the asset share invested in real estate market. Also note that the coefficient of self-employment was -0.171 at $5 \%$ significant level, which implying the intuitive of self-employment triggers the household investless proportion of wealth in real estate market, instead, invest more assets in profit-generating projects.

Table 3. Mechanism of happiness effects

\begin{tabular}{|l|c|c|c|c|}
\hline & \multicolumn{2}{|c|}{ Less Optimistic Household } & \multicolumn{2}{c|}{ Optimistic Household } \\
\hline & IV/Probit & IV/Tobit & IV/Probit & IV/Tobit \\
\hline Happiness & $1.1858^{* * *}$ & 0.7080 & $0.9915^{* * *}$ & 0.1478 \\
\hline & $(0.1177)$ & $(0.6270)$ & $(0.2200)$ & $(0.1047)$ \\
\hline Controls & Yes & Yes & Yes & Yes \\
\hline Observations & 1341 & 1659 & 5916 & 6291 \\
\hline
\end{tabular}

Notes: Robust standard errors are in parentheses. * Significant at the $10 \%$ level; ** Significant at the $5 \%$ level; *** Significant at the $1 \%$ level.

Finally, this article propose optimism as a channel through which happiness might influence household's real estate investment. Happy household might be more optimistic, and have higher expectation regarding the long-term growth of economy, and appreciate the market risk premium. The results of mechanism examination in Table 3columns (1) and (3) show that the coefficients of probability of participation in real estates for both less optimistic and optimistic subsamples are significant, implying a possible channel that happy household might have higher level of optimism to raise their participation rates in real estate market. However, in columns (2) and (4), the coefficients are not statistically significant, suggesting no correlation between happiness and share of wealth in real estate is driven by household optimism. 


\section{Conclusion}

By using data from the CHFS, this article investigated the role of happiness on probability of participation and proportion of wealth investing in real estate market. This article concludes two major findings. First, this empirical study identifies that happiness significantly impacts households' decision regarding investing real estate, and happy household invest more share of household wealth in real estate. Another important caveat in this context reveal that optimism provides a potential channel to influence the real estate market participation. Nevertheless, the optimism has a limited impact on the allocation of share of assets of household in term of real estate. To maintain fast, durable and sustainable economy in China, further study is required to rethink the impact of happiness on growth of real estate market.

\section{Reference}

[1] J. Y. Campbell, Household Finance, Journal of Finance, 4 (2006) 1553-1604.

[2] P. Tufano, Consumer Finance. Annual Review of Financial Economics, 1 (2009) 227-247.

[3] A. Vissing-Jorgensen, Towards an explanation of household portfolio choice heterogeneity: Nonfinancial income and participation cost structures. National Bureau of Economic Research. (2002).

[4] B. D. Bernheim, D. M. Garrett, The determinants and consequences of financial education in the workplace: Evidence from a survey of households. National Bureau of Economic Research. (1996).

[5] H. Hong, J. D. Kubik, J. C. Stein, Social interaction and stock-market participation. The journal of finance, 59 (2004) 137-163.

[6] D. Gilbert, Stumbling on happiness. Vintage. (2006).

[7] B. E. Kahn, A. M. Isen, The influence of positive affect on variety seeking among safe, enjoyable products. Journal of Consumer Research, 20 (1993) 257-270.

[8] B. S. Frey, A. Stutzer, (2002). What can economists learn from happiness research? Journal of Economic literature, 40 (2002) 402-435.

[9] C. Guven, Reversing the question: Does happiness affect consumption and savings behavior? Journal of Economic Psychology, 33 (2012) 701-717.

[10] Y. Rao, L. Mei, R. Zhu, Happiness and Stock-Market Participation: Empirical Evidence from China, Journal of Happiness Studies. 11 (2014) 1-23. 